Thi Kim Ngan Nguyen, Hong Gun Kim, Lee Ku Kwac, Quoc Bao Bui, Dang Mao Nguyen* and Hun Jeong*

\title{
Titanium dioxide-benzophenone hybrid as an effective catalyst for enhanced photochemical degradation of low density polyethylene
}

https://doi.org/10.1515/epoly-2018-0078

Received April 11, 2018; accepted May 5, 2018; previously published online August 20, 2018

Abstract: In this study, a hybrid of titanium dioxide, benzophenone and ethylene vinyl acetate $\left(\mathrm{TiO}_{2}\right.$-BP-EVA) was used as a novel catalyst to accelerate photo-oxidization reaction of low-density polyethylene (LDPE) film under ambient conditions. The degradation of the LDPE films (thickness of $\sim 25 \mu \mathrm{m}$ ) containing different catalyst concentrations were successfully investigated by different techniques, such as Fourier-transform infrared (FT-IR) spectroscopy, field emission scanning electron microscopy (SEM), differential scanning calorimetry (DSM), thermogravimetric analysis (TGA) and mechanical tests. The results showed that the use of catalyst in which $\mathrm{TiO}_{2}$ - $\mathrm{BP}$ content $(1 / 3 \mathrm{w} / \mathrm{w})$ is $0.5 \mathrm{phr}$ (parts per hundred resin) and EVA content is $4.5 \mathrm{phr}$ in a LDPE film provided the best degradation rate. The carbonyl index of the polymer film achieved the highest value without an equilibrium stage. Besides, the carbon-carbon backbone of the polymer was completely broken down consistent with the deformation of the surface. In addition, the mechanical properties impressively dropped after 3 months' exposure. The obtained results imply that the $\mathrm{TiO}_{2}$-BP-EVA compound

*Corresponding authors: Dang Mao Nguyen, PhD, Department of Polymer and Composite Materials, Faculty of Material Science, University of Science, Vietnam National University Ho Chi Minh City (VNU), Ho Chi Minh City, Vietnam; and LOCIE, Polytech AnnecyChambery, Université de Savoie Mont Blanc, Campus Scientifique, 73376 Le Bourget du Lac Cedex, France, e-mail: ndmao@hcmus.edu.vn; and Hun Jeong, PhD, Institute of Carbon Technology, Jeonju University, Jeonju, Jeonbuk 55069, Republic of Korea, e-mail: feerself@jj.ac.kr

Thi Kim Ngan Nguyen: Fine Particles Engineering Group, National Institute for Material Science, Tsukuba, Ibaraki 305-0047, Japan; and Department of Polymer and Composite Materials, Faculty of Material Science, University of Science, Vietnam National University Ho Chi Minh City (VNU), Ho Chi Minh City, Vietnam Hong Gun Kim and Lee Ku Kwac: Institute of Carbon Technology, Jeonju University, Jeonju, Jeonbuk 55069, Republic of Korea Quoc Bao Bui: Sustainable Developments in Civil Engineering Research Group, Faculty of Civil Engineering, Ton Duc Thang University, Ho Chi Minh City, Vietnam can be considered as an efficient catalyst for the photodegradation of LDPE polymer.

Keywords: benzophenone; catalyst; photodegradation; polyethylene film; titanium dioxide.

\section{Introduction}

Nowadays, polymer-based materials have been widely applied in various applications due to useful properties, including toughness, high strength/modulus, transparency, light weight, resilience, corrosion resistance, low thermal and electrical conductivity, color, processing and cost effectiveness (1-7). Among the diverse polymers, low-density polyethylene (LDPE) has been widely used in industrial packaging because of its unique advantages, such as good flexibility, high mechanical properties and being a good air barrier. Nowadays, large amounts of post-consumer LDPE products are discarded every year, causing major problems for economies and pollution due to its non-biodegradability. Regarding the degradability of LDPE, LDPE film has been demonstrated to lose about $0.2 \%$ weight after 10 years (8) and white spots appeared on its surface after being buried in soil for 32 years (9). Therefore, specific approaches have been developed to efficiently accelerate the degradation of LDPE (10-15). In this regard, LDPE should be depolymerized to low molecular size of about 500 Da (Daltons) which can possibly be consumed by several kinds of microorganisms through passing through the semi-permeable outer bacterial membranes; then it can be used as carbon and energy sources (16). Recently, it was found that the degradable mechanism of LDPE critically depends on the creation of the radicals on the $\mathrm{C}$-C backbone, followed by completely breaking down into small chains through photochemical reaction under ultraviolet-visible (UV) light. Therefore, the initial photooxidization for the creation of hydrophilic functional groups such as ketone, carboxylic acid, vinyl, alcohol and ester, plays an important role in supporting the approach of bacteria on polymer chains, then promoting for subsequent biodegradable stages. In order to promote the chain scission of LDPE, the transition metal complexes and metal oxides, 
such as Co (17, 18), Fe-Ca (19), Mn-Fe-Co (20) and $\mathrm{TiO}_{2}(21)$ have been widely applied. In addition, montmorillonite modified by alkyl ammonium supporting the degradation of PE was also recently reported (22). It was demonstrated that the addition of $20 \mathrm{wt} \%$ of titania nanoparticles (NPs) under a humid environment caused weight loss of $60 \%$ for PE film after exposure for 90 days under visible light (23). The improved degradability of the LDPE was also further informed by a catalytic hybrid of titania and starch (24). Recently, $\mathrm{TiO}_{2}$ has emerged as a potential photocatalyst for PE degradation due to its high catalytic activity, nontoxicity and it being an excellent initiator for photochemical reactions $(25,26)$. To further improve the performance of $\mathrm{TiO}_{2}$ catalyst, the hybridization of $\mathrm{TiO}_{2}$ with some other agents, such as sulfate (27), calcium phosphate (28) and polyvinyl acetate (PVAc) (21) has been successfully established. In particular, the use of some hydrophilic polymers, including poly (ethylene oxide) and PVAc can greatly promote the photo-oxidized initial ability of $\mathrm{TiO}_{2}$ during $\mathrm{PE}$ degradation $(29,30)$. Impressively, the activity of $\mathrm{TiO}_{2}$ was impressively enhanced 5 times higher than pure $\mathrm{TiO}_{2}$ or pure benzophenone (BP) by incorporating $\mathrm{TiO}_{2}$ with $\mathrm{BP}$ at a $1 / 3(\mathrm{w} / \mathrm{w})$ ratio of $\mathrm{TiO}_{2} / \mathrm{BP}(31)$.

Although numerous reports focusing on the $\mathrm{PE}$ degradation using transitional metal ions have been discussed, to the best of our knowledge, there is no available report which thoroughly investigated the effect of a novel hybrid based on $\mathrm{TiO}_{2}$, $\mathrm{BP}$ and ethylene vinyl acetate (EVA) towards the photodegradation of LDPE. Therefore, in this study, we developed an effective catalyst via a combination of $\mathrm{TiO}_{2}, \mathrm{BP}$ and EVA with an optimized weight ratio to investigate the degradation of LDPE films. The obtained results showed that such catalyst exhibited a superior effect on the degradability of LDPE in which the polymer film is completely broken down into small species after 3 months, as compared to pure $\mathrm{TiO}_{2}$ or its BP counterpart.

\section{Materials and methods}

\subsection{Materials}

The low-density polyethylene (LDPE, code $2426 \mathrm{H}$ ) was purchased from Eastern Petrochemical Co. Ltd (Jubail city, Saudi Arabia). $\mathrm{TiO}_{2}$ (code Ti-Pure ${ }^{\circledR} \mathrm{R} 902+$ ) and polyvinyl acetate copolymer (EVA 18) was supplied by DuPont Co. (Wilmington city, NC, USA). Benzophenone with a molecular weight of $182.22 \mathrm{~g} / \mathrm{mol}$, density of $1.11 \mathrm{~g} / \mathrm{cm}^{3}$ and melting temperature of $47-49^{\circ} \mathrm{C}$, was purchased from Sigma-Aldrich Co. (Missouri city, TX, USA).

\subsection{Preparation of LDPE/TiO 2 -BP-EVA catalysts}

The masterbatches of $\mathrm{TiO}_{2}$-BP-EVA were firstly prepared using a mixing process in a Polydrive Haake mixer (Germany) at rotation rate of $80 \mathrm{rpm}$ (rpm: the number of rotations in $1 \mathrm{~min}$ ) and $120^{\circ} \mathrm{C}$ for $10 \mathrm{~min}$. The obtained $\mathrm{TiO}_{2}$-BP-EVA material was cut into small pieces with the size of $1 \mathrm{~cm}^{2}$ and was then mixed with the LDPE matrix. The $\mathrm{LDPE} / \mathrm{TiO}_{2}$-BP-EVA films with the thickness of $\sim 25 \mu \mathrm{m}$ were prepared using a laboratory-scale twin-screw extruder Haake Rheomex OS PTW16 with L/D ratio of 25:1 and a diameter of $19 \mathrm{~mm}$. The synthesis conditions on the Haake Rheomex were controlled with four zone temperature profiles, including a feed zone with $150^{\circ} \mathrm{C}$, a compression zone with $165^{\circ} \mathrm{C}$, a metering zone with $175^{\circ} \mathrm{C}$ and a die zone with $190^{\circ} \mathrm{C}$. The components for preparing the LDPE/ $\mathrm{TiO}_{2}$-BP-EVA films are listed in Table 1.

\subsection{Evaluation of the photodegradation of polymer film}

The degradation of LDPE films was investigated according to ASTM D1435-99 standard. The specimens were cut at $10 \times 15 \mathrm{~cm}^{2}$ size, fixed on the plank and turned to a southwestern site with $45^{\circ}$ angle to the ground. The specimens were continually exposed to the natural weather for 3 months. The weather conditions during this test were measured in a range of $60-80 \%$ relative humidity using a moisture meter and the temperature in a range of 25 and $38^{\circ} \mathrm{C}$ using a thermometer. The samples were then collected, washed with distilled water and dried at $50^{\circ} \mathrm{C}$ to evaluate the carbonyl index every 2 weeks and for measuring the mechanical properties every 4 weeks.

\subsection{Determination of the carbonyl index (ICO)}

The samples investigated the carbonyl index using the band index method through the use of Fourier-transform infrared (FT-IR) spectroscopy on an IR Affinity-1 (Shimazu) spectrophotometer. The ICO value was defined as the ratio

Table 1: The composition of $\mathrm{LDPE} / \mathrm{TiO}_{2}$-BP-EVA films.

\begin{tabular}{lrrrrr}
\hline Sample name & LDPE (g) & EVA (g) & $\mathrm{TiO}_{2}(\mathbf{g})$ & BP $_{(g)}$ & $\mathrm{TiO}_{2}: \mathbf{B P}(1: 3)$ \\
\hline LDPE & 100 & - & - & - & - \\
ET & 100 & 4.5 & 0.5 & - & - \\
EB & 100 & 4.5 & - & 0.5 & - \\
$4.5 E T 1$ & 100 & 4.5 & - & - & 0.5 \\
4 ET1 & 100 & 4 & - & - & 1 \\
$3.5 E T 1$ & 100 & 3.5 & - & - & 1.5 \\
\hline
\end{tabular}


between the carbonyl vibrational band at $1717 \mathrm{~cm}^{-1}$ and $-\mathrm{CH}_{2}$-strength vibrational band at $1464 \mathrm{~cm}^{-1}$ (32).

$\mathrm{ICO}=$

Absorption at $1717 \mathrm{~cm}^{-1}$ (the maximum of carbonyl peak) Absorption at $1464 \mathrm{~cm}^{-1}$ (internal thickness band)

\subsection{Mechanical tests}

The mechanical properties of LDPE films containing catalysts before and after the photodegradation were measured according to the ASTM D882 standard by means of the AG-X plus Series Precision Universal Tester (Shimadzu Inc., Japan). All the test samples were conditioned at $25^{\circ} \mathrm{C}$ for $24 \mathrm{~h}$ before any measurement. The average values of the average Young's modulus, strength and elongation at break were calculated from five measurements for each sample.

\subsection{Morphology characterization}

The surface morphology of the LDPE films after photodegradation was characterized using a Field Emission Scanning Electron Microscopy Hitachi S-4800 (Hitachi Co., Japan).

\subsection{Thermal analysis}

Differential scanning calorimeter (DSC) measurements of LDPE films were performed using the PT1000 DSC (Mettler Toledo Co., Switzerland), under the nitrogen flow rate of $30 \mathrm{ml} / \mathrm{min}$ and a heating rate of $10^{\circ} \mathrm{C} / \mathrm{min}$. The samples were heated from $25^{\circ} \mathrm{C}$ to $140^{\circ} \mathrm{C}$, then cooled to $-50^{\circ} \mathrm{C}$ before being reheated to $140^{\circ} \mathrm{C}$ again. The melting temperature $\left(\mathrm{T}_{\mathrm{m}}\right)$, enthalpy of fusion $(\Delta \mathrm{H})$ and crystallize temperature $\left(T_{c}\right)$ were determined from DSC thermographs. The crystallinity $\left(X_{c}\right)$ of polymer was calculated according to the following equation:

$$
\% X_{c}=\frac{\Delta H}{w \times \Delta H_{f_{0}}} \times 100
$$

where $\Delta H$ is the enthalpy of fusion obtained from the DSC curve, $\Delta H_{f_{0}}$ is the enthalpy heat of a $100 \%$ crystalline polymer $(289 \mathrm{~J} / \mathrm{g})(33)$, and $w$ is the weight fraction of the LDPE.

Thermal stability of the films before and after photodegradation was performed using a TGA Q500 (TA Instruments Co., USA) under the nitrogen flow rate of $50 \mathrm{ml} / \mathrm{min}$. The samples were heated from room temperature to $600^{\circ} \mathrm{C}$ at the heating rate of $10^{\circ} \mathrm{C} / \mathrm{min}$ in order to investigate the thermal degradation of the samples.

\section{Results and discussion}

\subsection{Influence of $\mathrm{TiO}_{2}$-BP-EVA on the photodegradation of LDPE film}

The FT-IR method is basic technique to evaluate the effect of photocatalyst on the degradation of polymers through the carbonyl index and functional groups created during exposure $(16,18,21,34-39)$. Figure 1 indicates the FT-IR spectrum of pure LDPE film after 3 months' exposure, which

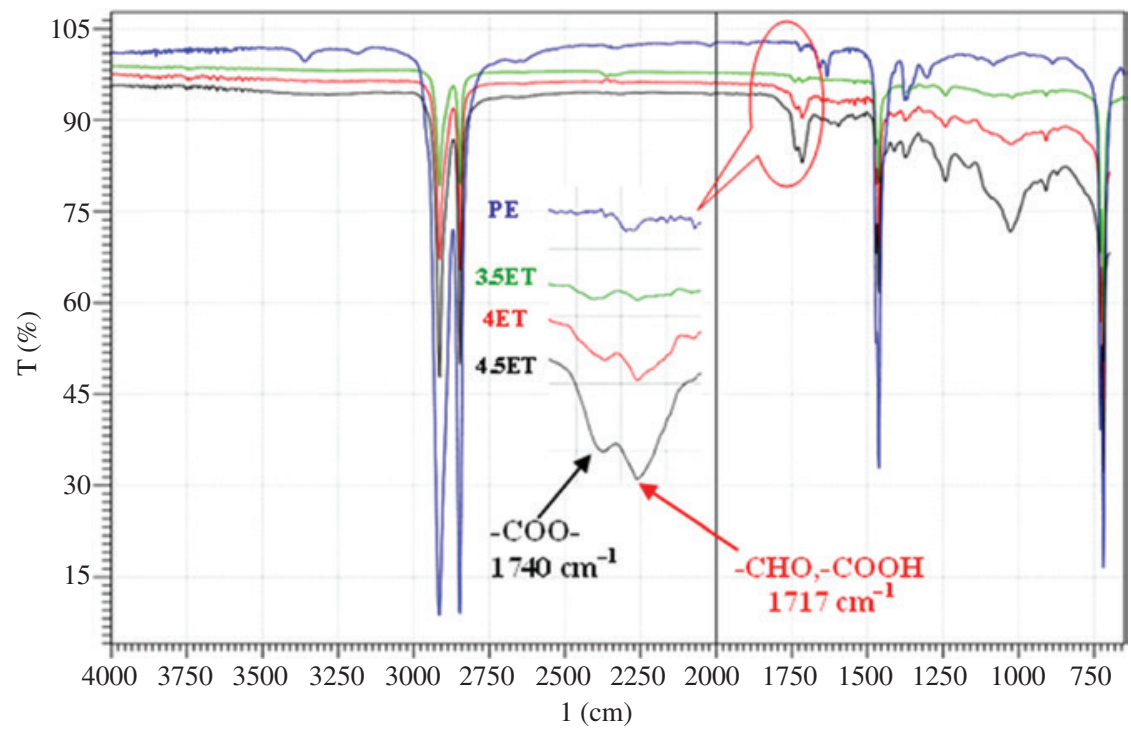

Figure 1: FT-IR spectra of LDPE, 4.5ET1, 4ET1 and 3.5ET1 films after degradation for 3 months. 
includes strong intensity of the $\mathrm{C}-\mathrm{H}$ stretch vibrational band in wavenumber range of $2800 \mathrm{~cm}^{-1}$ and $2900 \mathrm{~cm}^{-1}$, the blade of the $-\mathrm{CH}_{2}$ - scissor vibrational band at $1464 \mathrm{~cm}^{-1}$, and the $-\mathrm{CH}_{2}$ - strings vibrational band at $722 \mathrm{~cm}^{-1}$. Meanwhile, the FT-IR spectra of the LDPE films containing different ratios of the $\mathrm{TiO}_{2}$-BP-EVA catalyst after 3 months' degradation involve the existence of additional bands, such as the $\mathrm{C}=\mathrm{O}$ vibrational band from ketone or aldehyde at $1717 \mathrm{~cm}^{-1}$ and the lower intensity peak of the $\mathrm{C}=\mathrm{O}$ stretching vibrational band from an ester at $1740 \mathrm{~cm}^{-1}$. In addition, there was the symmetric stretching oscillations of the C-O-C vibration at $1242 \mathrm{~cm}^{-1}$ and the fluctuating asymmetry stretching of the $\mathrm{C}-\mathrm{O}-\mathrm{C}$ vibration at $1021 \mathrm{~cm}^{-1}$. It can be seen that the 4.5ET1 film containing $5 \mathrm{phr}$ (parts per hundred resin) of the $\mathrm{TiO}_{2}^{-}$ BP-EVA catalyst with 0.125:0.375:4.5 ratio in LDPE achieves the higher intensity of $\mathrm{C}=\mathrm{O}$ vibrational bands which originated from the aldehyde or carboxylic acid, as compared with the LDPE 4ET1 and 3.5ET1 films. Similar characteristics were also confirmed by previous reports with the formation of ester, ketone, aldehyde and carboxylic groups after the photodegradation of the polymer (21).

In order to evaluate the initialization of photooxidization by the catalyst in the LDPE film, the gradient of the ICO value was continually recognized during the 3 months' exposure under sunlight. As revealed in the results in Figure 2, the ICO value of the LDPE film containing BP is higher than that of the film that contains $\mathrm{TiO}_{2}$ at the same exposure time. This result implies that the initialization of photooxidization caused by BP is more prominent than $\mathrm{TiO}_{2}$ in LDPE films. Meanwhile, the hybrid catalyst based on $\mathrm{TiO}_{2}$-BP-EVA shows the best effect which is associated with the impressive ICO value, being much higher than the other samples at the same exposure time. In addition, the ICO values of all the samples show the increasing tendency

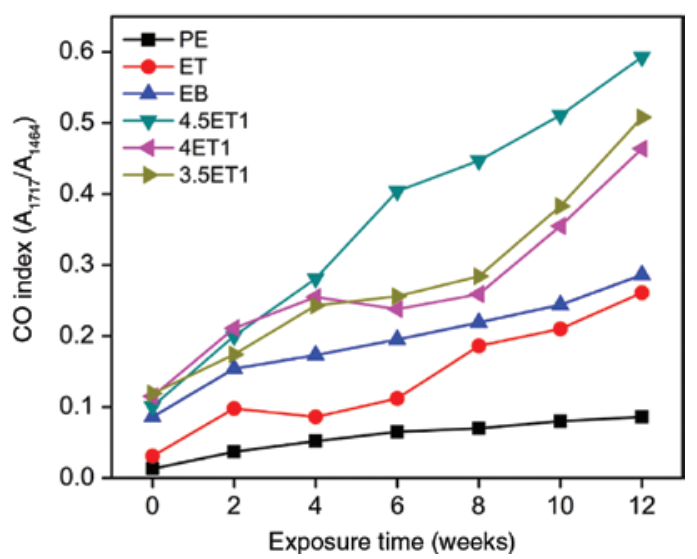

Figure 2: ICO values of different samples during photochemical degradation for 3 months. at different speeds over the 3 months. The ICO value of pure LDPE film increases very slowly. The ICO values of the ET and EB films increase fast but are still lower than that of the 4ET1 and 3.5ET1 films. The impressive increase in the ICO value was observed for the 4.5ET1 film with a high ICO value of 0.59 after 3 months, much higher than that of ET (0.261), EB (0.286), 4ET1 (0.464) and 3.5ET1 (0.508). This was due to the fact that the use of EVA can enhance the compatibility between the LDPE matrix and the catalyt, thereby falilitating the good dispersion of the catalyst in LDPE, then uniformly catalyzing the degradation at the carbon chain scale of LDPE. In addition, the EVA could be degraded to form ketone functional groups through the Norrish III reaction under UV light $(40,41)$ for increasing water absorption. Therefore, the subsequent reaction between $\mathrm{TiO}_{2}$ and water under UV light will accelerate to create more radicals on the carbon backbone of the LDPE polymer, then for promoting photodegradation.

The mechanisms of photodegradation of an LDPE film caused by the $\mathrm{TiO}_{2}$-BP-EVA catalyst is described in Figure 3. $\mathrm{TiO}_{2}$ is well known as a strong oxidizing agent based on the absorption of energy under sunlight. The first free radicals such as $\mathrm{OH}^{\circ}$ and $\mathrm{HOO}^{\circ}$ were created by photooxidization when $\mathrm{TiO}_{2}$ directly reacted with $\mathrm{H}_{2} \mathrm{O}$ molecules under the irradiation of sunlight $(26,42)$. In the similar way, the BP molecule absorbs sunlight energy in the steady state to transfer to the excited state that is so durable on BP and easily transfers to other BP molecules in order to create the radicals and continue initiating for carbon molecules on polymer $(18,43)$. Afterward, the radical products will continually react with $\mathrm{H}$ atoms on the carbon chains to create new free radicals on the main carbon chains. By adsorbing strong energy from sunlight, the new free radicals can react with oxygen atoms in order to form peroxide and hydroperoxide products which are immediately dehydrated to form ketone (44).

For the next stage, derivatives of ketone will interact with UV light to form carboxylic acid by the Norrish I mechanism or aldehyde or vinyl are formed by the Norrish II reaction (21). In addition, ketones and aldehydes are also formed from the ester by the III Norrish reaction (41). Therefore, the final products of the LDPE photodegradation include ketones, esters, carboxylic acid, vinyl and alcohol groups which are potential candidates to accelerate the biodegradation of polyethylene in the soil.

\subsection{Morphology of LDPE films during photo-degradation}

Figure 4 shows the optical images and scanning electron microscopy (SEM) images of the LDPE films containing 

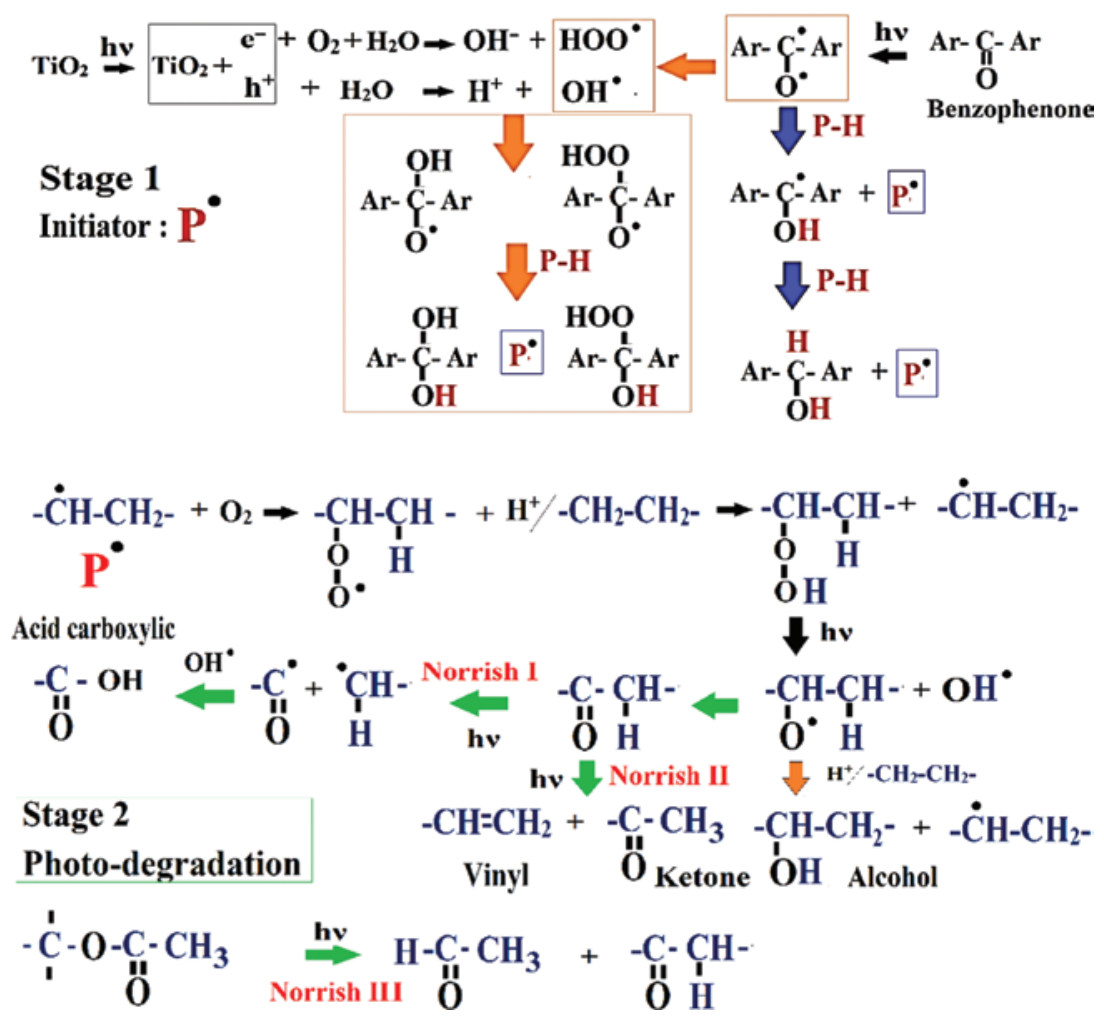

Figure 3: Photooxidation mechanisms of on LDPE film caused by $\mathrm{TiO}_{2}$-BP-EVA catalyst.

different ratios of catalyst after 3 months' exposure. From optical images, the pure LDPE sample exhibits a smooth and homogeneous surface without observation of the degradation phenomenon (Figure 4A). The 4ET1 and 3.5ET1 films showed the rough, embrittlement and brittle surfaces (Figure 4E and G), meanwhile the 4.5ET1 film exhibited being completely damaged into small pieces (Figure 4C). At micro observation, SEM images of pure LDPE still display smooth and homogeneous surfaces, which further confirmed no photodegradation of the LDPE film after 3 months (Figure 4B). Whereas, the microstructure of the 4.5ET1 film becomes scabrous, deformed and has more numerous large holes, which is evidence of the photodegradation caused by the optimized $\mathrm{TiO}_{2}^{-}$ BP-EVA catalyst (Figure 4D). In this regard, the enhanced fragmentation of the LDPE film was due to the depolymerization of the LDPE chains to the low molecular size of 500 Da (Daltons), which can be consumed by several microorganisms in a further stage $(9,16)$. The 4ET1 film containing a high $\mathrm{TiO}_{2} / \mathrm{BP}$ content of $1 \mathrm{phr}$ also shows the decomposition with some small holes, but less than that of 4.5ET1 surface (Figure 4F). This implies that increasing the amount of photocatalyst would reduce the triggered performance during photodegradation leading to less deformed surface films. In the case of the 3.5ET1, which contains the highest amount of $\mathrm{TiO}_{2}$-BP-EVA (about 1.5\% phr), was recognized by the presence of 3-5 $\mu \mathrm{m}$ size particles of catalyst without the formation of holes on the surface of the film (Figure 4H). This result may be due to the accumulation of the catalyst, which cannot homogeneously disperse in the matrix film; therefore, it cannot promote photodegradation by increasing the triggered area when the films are exposed under sunlight.

\subsection{Thermal analysis of films after the photo-degradation test}

The thermal properties of samples before and after degradation were investigated by DSC equipment from $25^{\circ} \mathrm{C}$ to $140^{\circ} \mathrm{C}$. LDPE and EVA are well known as semi-crystalline polymers, they are compatible in the amorphous region and incompatible in the crystalline phase (41). The amorphous regions of the LDPE/EVA blend had an influence on the photochemical stabilization and also affected their crystallization behavior (21). As presented in Table 2, the melting temperatures of all the initial samples containing different ratios of catalyst show almost the same values after the degradation process, implying that the presence of catalyst causes a minor influence on the crystallinity 

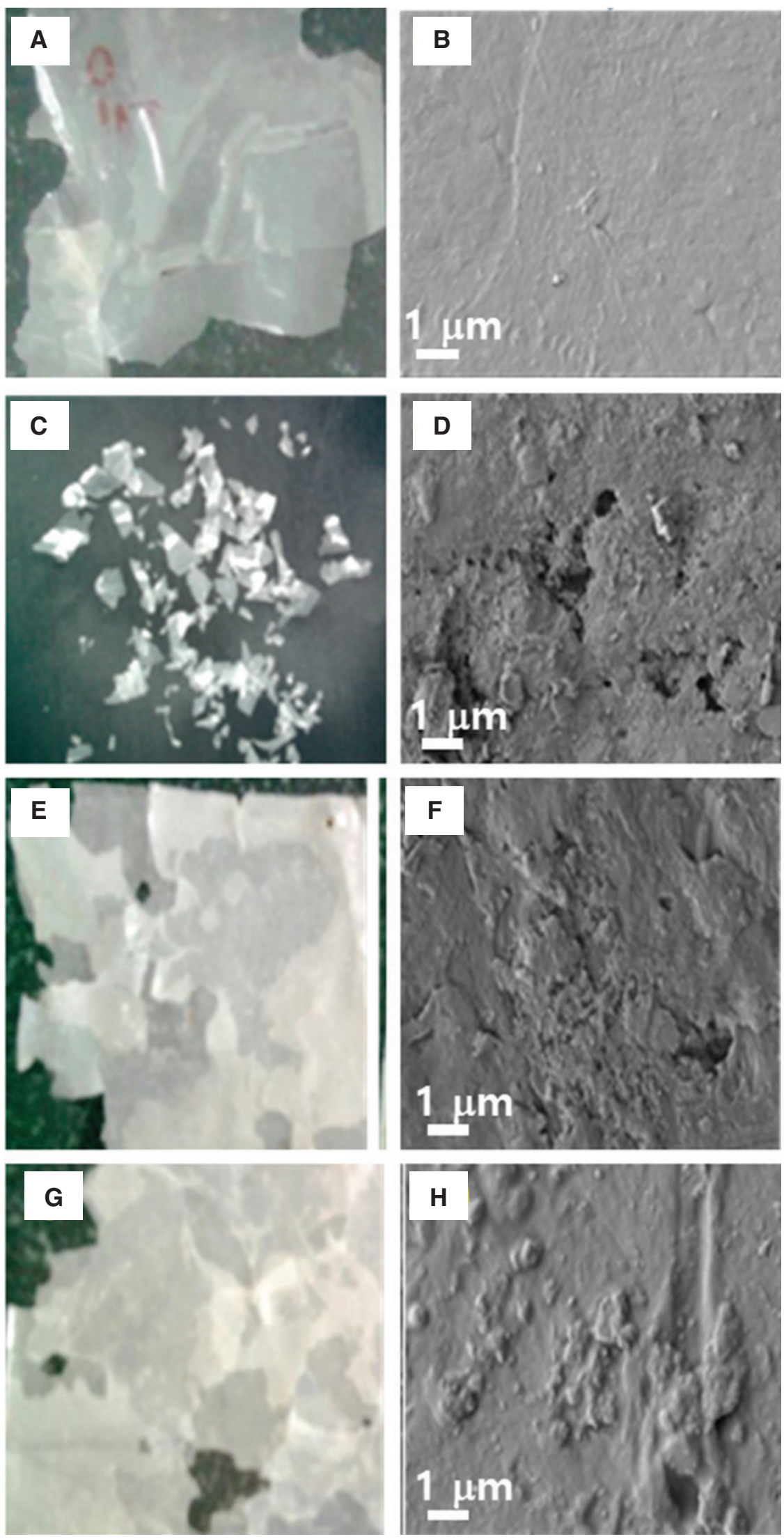

Figure 4: The photos and surface morphology of films after 3 months' photochemical degradation. (A) Optical photo and (B) SEM image of LDPE; (C) optical photo and (D) SEM image of 4.5ET1; (E) optical photo and (F) SEM image of 4ET1; and (G) optical photo and (H) SEM image of 3.5ET1 material. 
Table 2: The melt temperature and crystallinity $\left(\chi_{c}\right)$ of the films before and after 3 months' exposure.

\begin{tabular}{|c|c|c|c|c|c|c|c|}
\hline \multirow[t]{2}{*}{ Sample } & \multirow{2}{*}{$\begin{array}{r}\text { Aging time } \\
\text { (days) }\end{array}$} & \multicolumn{3}{|c|}{ 1st heating } & \multicolumn{2}{|c|}{ 2nd heating } & \multirow{2}{*}{$\frac{\text { Crystallinity }}{\boldsymbol{\chi}_{\mathrm{c}}(\%)}$} \\
\hline & & $\mathrm{T}_{\text {on }}\left({ }^{\circ} \mathrm{C}\right)$ & $\mathrm{T}_{\text {peak }}\left({ }^{\circ} \mathrm{C}\right)$ & $\chi_{c}(\%)$ & $\mathrm{T}_{\text {on }}\left({ }^{\circ} \mathrm{C}\right)$ & $\mathrm{T}_{\text {peak }}\left({ }^{\circ} \mathrm{C}\right)$ & \\
\hline \multirow[t]{2}{*}{ LDPE } & 0 & 104 & 111 & 23.56 & 104 & 110 & 24.90 \\
\hline & 90 & 106 & 111 & 27.26 & 105 & 112 & 25.04 \\
\hline \multirow[t]{2}{*}{ 4.5ET1 } & 0 & 106 & 109 & 36.62 & 104 & 111 & 37.85 \\
\hline & 90 & 106 & 113 & 49.54 & 105 & 112 & 43.52 \\
\hline \multirow[t]{2}{*}{ 4ET1 } & 0 & 106 & 109 & 31.51 & 104 & 111 & 33.38 \\
\hline & 90 & 105 & 111 & 46.56 & 104 & 111 & 40.23 \\
\hline \multirow[t]{2}{*}{ 3.5ET1 } & 0 & 106 & 109 & 33.96 & 104 & 110 & 35.51 \\
\hline & 90 & 105 & 112 & 46.46 & 104 & 111 & 41.18 \\
\hline
\end{tabular}

of LDPE. The melting temperatures of the samples after degradation are slightly increased by about $1-3^{\circ} \mathrm{C}$, as compared to the initial samples. This is due to the increase of crystallinity degree $\left(\chi_{c}\right)$ in which the $\mathrm{TiO}_{2}$ acts as a nucleating agent for the crystallization of $\operatorname{LDPE}(45,46)$. Besides, the reorganization of the fractured chains after aging also influences on the increase of $\chi_{c}$. In this regard, the long carbon chains of the polymer matrix are decomposed to shorter chains by photooxidization with $\mathrm{CO}$ functional group at the last circuit. The carbon backbone chains significantly improved the mobility that promotes the rearrangements of them to form perfect crystalline areas, leading to increasing the crystallinity compared to samples that do not age $(21,47)$.

\subsection{The mechanical properties of LDPE films}

The tensile properties of various samples were investigated to evaluate the influence of the catalyst on the degradability of LDPE after 3 months. Figure 5 shows the mechanical properties of LDPE films before and after 3 months' storage without exposure to sunlight. The results imply that the LDPE films containing $\mathrm{TiO}_{2}$-BP cannot be photodegraded if they do not have contact with sunlight.

Figure 6 shows the tensile strength and elongation of samples before and after 3 months' storage under sunlight. The pure LDPE film possesses tensile strength of $23.7 \mathrm{MPa}$ and elongation of $323 \%$. Other initial samples containing different amounts of $\mathrm{TiO}_{2}, \mathrm{BP}$ and $\mathrm{TiO}_{2}$ - $\mathrm{BP}$ showed nearly the same values of tensile strength and elongation as compared to pure LDPE. The tensile strength of ET (26 MPa) is higher than that of other samples due to reinforcement of $\mathrm{TiO}_{2}$ fillers in PE matrix. The tensile properties of all samples during exposure to natural weather conditions are significantly decreased after 1 month. The decrease in tensile properties is basically due to the increase in the embrittlement by increasing the cross-linking of the samples after aging (18). All samples became completely brittle after 2 months' and could not be collected for testing after 3 months, due to the fragmentation under photodegradation. The decrease of the elongation rate for samples containing the $\mathrm{TiO}_{2}$-BP catalyst was more rapid than others.
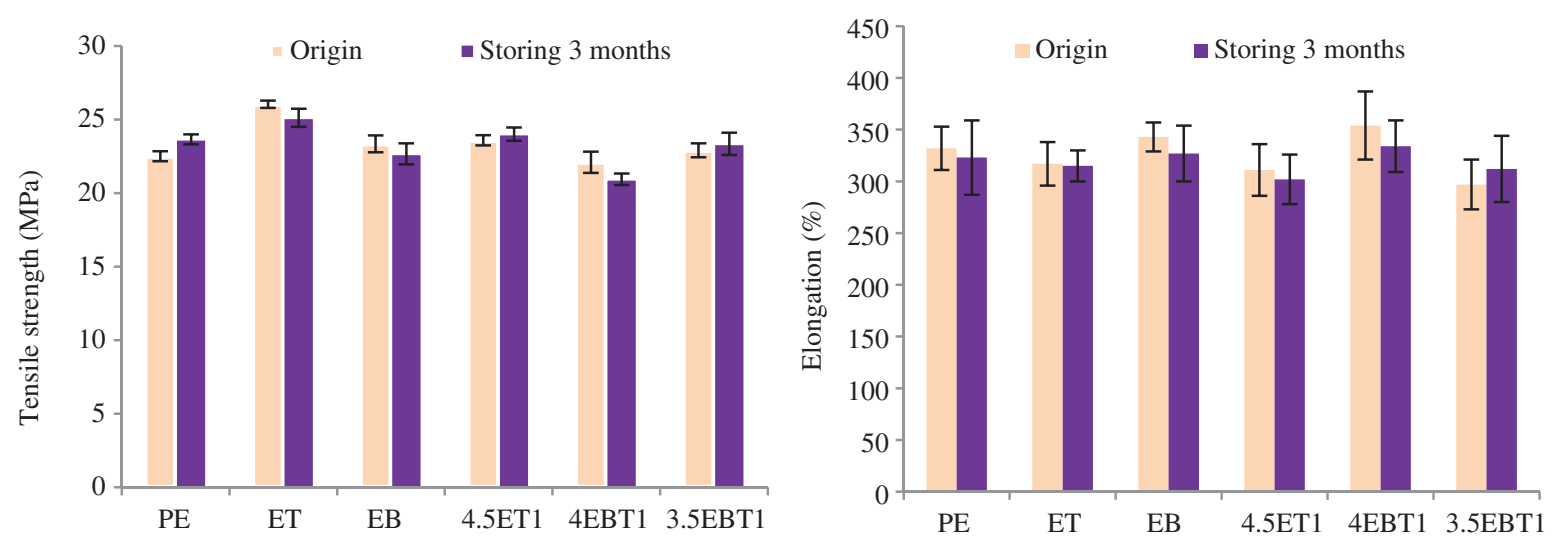

Figure 5: The tensile strength and elongation of different films after 3 months' storage without sunlight. 

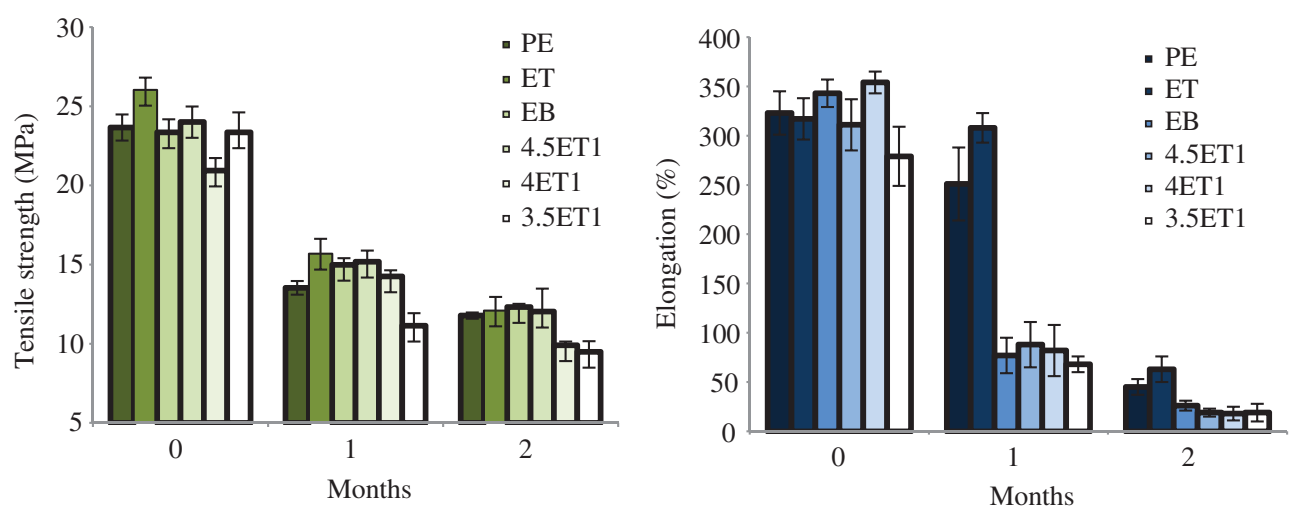

Figure 6: The tensile strength and elongation of different films during the photodegradable test.

\subsection{Thermal stability}

Figure 7 shows the influence of the catalyst on the thermal stability of the LDPE film before and after photochemical degradation. In the case of a pure LDPE film, the thermal decomposition of the PE film has only one shift which begins around $435^{\circ} \mathrm{C}$ with strong weight loss at $478^{\circ} \mathrm{C}$, the total weight loss is $100 \%(\mathrm{w} / \mathrm{w})$ at $500^{\circ} \mathrm{C}$. Regarding the 4.5ET1 film, the thermal decomposition begins at $423^{\circ} \mathrm{C}$ $\left(\mathrm{T}_{\mathrm{on}}\right), 13^{\circ} \mathrm{C}$ lower than that of a pure LDPE film due to the first step of thermal degradation of EVA, consistent with the deacylation of the vinyl acetate groups between $300^{\circ} \mathrm{C}$ and $400^{\circ} \mathrm{C}$. The strongest decomposition $\left(\mathrm{T}_{\text {peak }}\right)$ happened at $483^{\circ} \mathrm{C}, 5^{\circ} \mathrm{C}$ higher than that of a pure LDPE film, due to the high thermal stability of $\mathrm{TiO}_{2}(48,49)$. The total weight loss of $4.5 \mathrm{ET} 1$ sample reaches about $98.8 \%(\mathrm{w} / \mathrm{w})$ at $520^{\circ} \mathrm{C}$. The residual weight about $1.2 \%(\mathrm{w} / \mathrm{w})$ may be due to the presence of metal oxide in the sample. After aging for 3 months, the heat decomposition of 4.5ET1 samples shifted to the lower temperature region with $\mathrm{T}_{\text {on }}$ at $396^{\circ} \mathrm{C}$ and $\mathrm{T}_{\text {peak }}$ at $463^{\circ} \mathrm{C}$. The total weight loss of the $4.5 \mathrm{ET} 1$ sample reached about $100 \%(\mathrm{w} / \mathrm{w})$ at $500^{\circ} \mathrm{C}$, resulting from that the carbon chains of the LDPE being decomposed into shorter chains with reduced molecular weight, leading to a decrease of thermal stability. In addition, the formation of abundant unstable groups on the LDPE structure during the degradation process also promoted the thermal decomposition of LDPE at high temperatures $(18,21)$.

\section{Conclusion}

The ICO analysis, morphological structure, mechanical properties and thermal stabilization of the pure LDPE film and LDPE film containing photocatalysts indicated that the use of the $\mathrm{TiO}_{2}$-BP-EVA spurred the decomposition of LDPE film after 3 months under natural exposure. The LDPE films containing $4.5 \mathrm{phr}$ EVA and 0.5 phr $\mathrm{TiO}_{2}-\mathrm{BP}$ $(1 / 3 \mathrm{w} / \mathrm{w})$ resulted in the highest CO indicators, promoting the decomposition efficiency of LDPE. This study may open up a new direction for the manufacture of packaging with oxodegradable polymers.
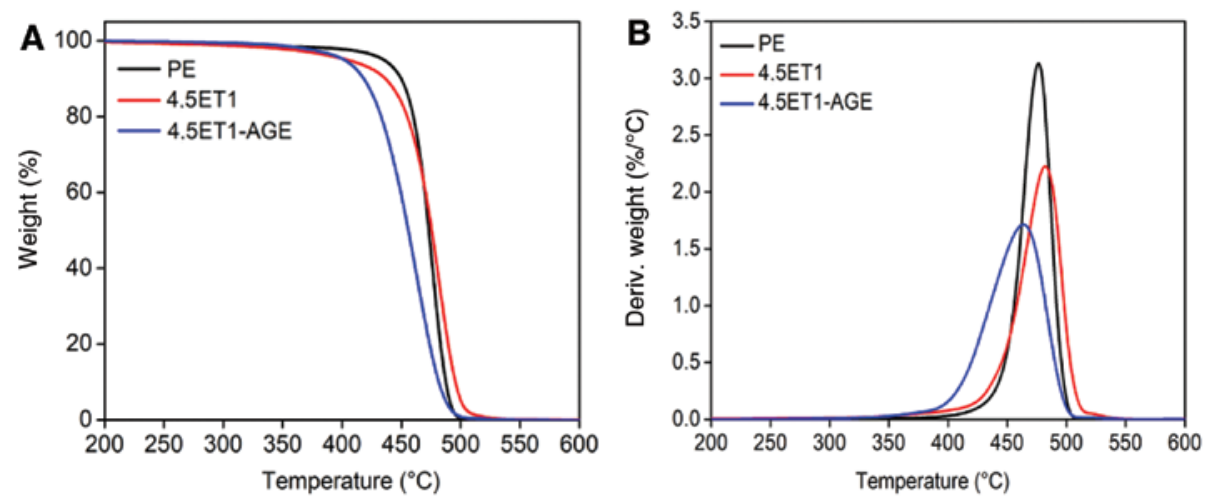

Figure 7: Influence of the catalyst on the thermal stability of the LDPE film.

TGA (A) and DTG (B) curves of 4.5ET1 and 4.5ET1-AGE after 3 months' degradation. 
Acknowledgment: The authors would like to acknowledge support from the Basic Science Research Program (2017R1D1A1B03028413) and (2016R1A6A1A03012069) through the National Research Foundation (NRF) funded by the Ministry of Education of Korea. This study was also supported by the Faculty of Material Sciences, Ho Chi Minh University of Science HCMC, and VNU-HCMC. We would like to thank our colleagues for their enthusiasm and cooperation in the study.

\section{References}

1. Sham AYW, Notley SM. A review of fundamental properties and applications of polymer-graphene hybrid materials. Soft Matter 2013;9:6645-53.

2. Thanh TD, Kaprálková L, Hromádková J, Kelnar I. Effect of graphite nanoplatelets on the structure and properties of PA6elastomer nanocomposites. Eur Polym J. 2014;50:39-45.

3. Nasir A, Kausar A, Younus A. A review on preparation, properties and applications of polymeric nanoparticle-based materials. Polym Plast Technol Eng. 2014;54:325-41.

4. Tran DT, Nguyen DM, Ha Thuc CN, Dang TT. Effect of coupling agents on the properties of bamboo fiber-reinforced unsaturated polyester resin composites. Compos Interfaces. 2013;20:343-53.

5. Mao ND, Thanh TD, Thuong NT, Grillet A-C, Kim NH, Lee JH. Enhanced mechanical and thermal properties of recycled ABS/ nitrile rubber/nanofil N15 nanocomposites. Compos Part B Eng. 2016;93:280-8.

6. Tran TD, Nguyen MD, Thuc CNH, Thuc HH, Tan TD. Study of mechanical properties of composite material based on polypropylene and vietnamese rice husk filler. J Chem. 2013;2013:752924.

7. Thanh TD, Mao ND, Ngan NTK, Nhan HTC, Huy HT, Grillet AC. Study structure and properties of nanocomposite material based on unsaturated polyester with clay modified by poly(ethylene oxide). J Nanomater. 2012;2012:841813.

8. Albertsson AC. The shape of the biodegradation curve for low and high density polyethylenes in prolonged series of experiments. Eur Polym J. 1980;16:623-30.

9. Otake Y, Kobayashi T, Ashabe H, Murakami N, Ono K. Biodegradation of lowdensity polyethylene, polystyrene, polyvinylchloride, and urea-formaldehyde resin buried under soil for over 32 years. J Appl Polym Sci. 1995;56:1789-96.

10. Nguyen DM, Do TVV, Grillet A-C, Ha-Thuc H, Ha-Thuc CN. Biodegradability of polymer film based on low density polyethylene and cassava starch. Int Biodeterior Biodegrad. 2016;115:257-65.

11. Nguyen DM, Vu TT, Grillet A-C, Ha-Thuc H, Ha-Thuc CN. Effect of organoclay on morphology and properties of linear lowdensity polyethylene and Vietnamese cassava starch biobased blend. Carbohydr Polym. 2016;136:163-70.

12. Thipmaneea R, Lukubirac S, Ogalec AA, Sanea A. Enhancing distributive mixing of immiscible polyethylene/thermoplastic starch blend through zeolite ZSM-5 compounding sequence. Carbohydr Polym. 2016;136:812-9.
13. Lu X, Tang L, Wang L, Zhao J, Li D, Wu Z, Xiao P. Morphology and properties of bio-based poly (lactic acid)/highdensity polyethylene blends and their glass fiber reinforced composites. Polym Test. 2016;54:90-7.

14. Lomakin SM, Rogovin SZ, Grachev AV, Prut EV, Alexanyan CV. Thermal degradation of biodegradable blends of polyethylene with cellulose and ethylcellulose. Thermochim Acta. 2011;521:66-73.

15. Volk N, He R, Magniez K. Enhanced homogeneity and interfacial compatibility in melt-extruded cellulose nano-fibers reinforced polyethylene via surface adsorption of poly(ethylene glycol)block-poly (ethylene) amphiphiles. Eur Polym J. 2015;72:270-81.

16. Shah AA, Hasan F, Hameed A, Ahmed S. Biological degradation of plastics: A comprehensive review. Biotechnol Adv. 2008;26:246-65.

17. Roy PK, Surekha P, Rajagopal C, Choudhary V. Effect of cobalt carboxylates on the photo-oxidative degradation of low-density polyethylene. Part-I. Polym Degrad Stab. 2006;91:1980-8.

18. Roy PK, Surekha P, Rajagopal C, Chatterjee SN, Choudhary V. Effect of benzil and cobalt stearate on the aging of low-density polyethylene films. Polym Degrad Stab. 2005;90:577-85.

19. Pablos JL, Abrusci C, Marín I, López-Marín J, Catalina F, Espí E, Corrales T. Photodegradation of polyethylenes: comparative effect of Fe and Ca-stearates as pro-oxidant additives. Polym Degrad Stab. 2010;95:2057-64.

20. Fontanella S, Bonhomme S, Koutny M, Husarova L, Brusson J-M, Courdavault J-P, Pitteri S, Samuel G, Pichon G, Lemaire J, Delort A-M. Comparison of the biodegradability of various polyethylene films containing pro-oxidant additives. Polym Degrad Stab. 2010;95:1011-21.

21. Liu Z, Jin J, Chen S, Zhang J. Effect of crystal form and particle size of titanium dioxide on the photodegradation behaviour of ethylene-vinyl acetate copolymer/low density polyethylene composite. Polym Degrad Stab. 2011;96:43-50.

22. Kumanayaka TO, Parthasarathy R, Jollands M. Accelerating effect of montmorillonite on oxidative degradation of polyethylene nanocomposites. Polym Degrad Stab. 2010;95:672-6.

23. Mehmood CT, Qazi IA, Baig MA, Arshad M, Quddos A. Enhanced photodegradation of titania loaded polyethylene films in a humid environment. Int Biodeterior Biodegrad. 2015;113:287-96.

24. Mehmood CT, Qazi IA, Hashmi I, Bhargava S, Deepa S. Biodegradation of low density polyethylene (LDPE) modified with dye sensitized titania and starch blend using Stenotrophomonas pavanii. Int Biodeterior Biodegrad. 2016;113:276-86.

25. Zan L, Fa W, Wang S. Novel photodegradable low-density polyethylene - TiO2 nanocomposite film. Environ Sci Technol. 2006;40:1681-5.

26. Manangan T, Shawaphun S, Sangsansiri D, Changcharoen J, Wacharawichanant S. Nano sized titanium dioxides as photocatalysts in degradation of polyethylene and polypropylene packagings. Sci J. 2010;1:14-20.

27. Colón G, Hidalgo MC, Munuera G, Ferino I, Cutrufello MG, Navío JA. Structural and surface approach to the enhanced photocatalytic activity of sulfated TiO2 photocatalyst. Appl Catal B Environ. 2006;63:45-59.

28. Miyazaki K, Shibata K, Nakatani H. Preparation of degradable polypropylene by an addition of poly(ethylene oxide) microcapsule containing Ti02, part III: effect of existence of calcium phosphate on biodegradation behavior. Polym Degrad Stab. 2011;96:1039-46. 
29. Allen NS, Edge M, Ortega A, Sandoval G, Liauw CM, Verran J, Stratton J, McIntyre RB. Degradation and stabilisation of polymers and coatings: nano versus pigmentary titania particles. Polym Degrad Stab. 2004;85:927-46.

30. Allen NS, Edge M, Ortega A, Liauw CM, Stratton J, McIntyre RB. Factors affecting the interfacial adsorption of stabilisers on to titanium dioxide particles (flow microcalorimetry, modelling, oxidation and FTIR studies): nano versus pigmentary grades. Dyes Pigm. 2006;70:192-203.

31. Manangan T, Shawaphun S, Kasetkulasheep K. Study of carbonyls-TiO2 as co-catalysts in photo-oxidative degradation of hydrocarbon backbone. Sci J Ubon Ratchathani Univ. 2010;1:27-34.

32. Abrusci C, Pablos JL, Corrales T, López-Marín J, Marín I, Catalina F. Comparative effect of metal stearates as pro-oxidant additives on bacterial biodegradation of thermal- and photo-degraded low density polyethylene mulching films. Int Biodeterior Biodegrad 2013;65:451-9.

33. Guo B, Zou Q, Lei Y, Du M, Liu M, Jia D. Crystallization behavior ofpolyamide $6 /$ halloysite nanotubes nanocomposites. Thermochim Acta 2009;484:48-56.

34. Abrusci C, Pablos JL, Corrales T, López-Marín J, Marín I, Catalina F. Biodegradation of photo-degraded mulching films based on polyethylenes and stearates of calcium and iron as pro-oxidant additives. Int Biodeterior Biodegrad. 2011;65:451-9.

35. Albertsson AC, Karlsson S. Aspects of biodeterioration of inert and degradable polymers. Int Biodeterior Biodegrad 1993;31:161-70.

36. Scott G. Photo-biodegradable plastics: their role in the protection of the environment. Polym Degrad Stab. 1990;29:135-54.

37. Gu J-D. Microbiological deterioration and degradation of synthetic polymeric materials: recent research advances. Int Biodeterior Biodegrad. 2003;52:69-91.

38. Hamilton JD, Reinert KH, Hogan JV, Lord WV. Polymers as solid waste in municipal landfills. J Air Waste Manage Assoc. 1995;43:247-51.
39. Barlaz MA, Schaefer DM, Ham RK. Bacterial population development and chemical characterization of refuse decomposition in a simulated sanitary landfill. Appl Environ Microbiol. 1989;55:55-65.

40. Dalai S, Chen WX. Radiation effects on LDPE/EVA blends. J Appl Polym Sci. 2002;86:1296-302.

41. Jin J, Chen S, Zhang J. UV aging behaviour of ethylene-vinyl acetate copolymers (EVA) with different vinyl acetate contents. Polym Degrad Stab. 2010;95:725-32.

42. Carpa O, Huismanb CL, Reller A. Photoinduced reactivity of titanium dioxide. Prog Solid State Chem. 2004;32:33-177.

43. Kubota H, Takahashi K, Ogiwara Y. Benzophenone-sensitized photo-degradation of polyolefins: Influence of benzophenone on model compounds. Polym Degrad Stab. 1991;33:115-23.

44. Yousif E, Haddad R. Photodegradation and photostabilization of polymers, especially polystyrene: review. SpringerPlus 2013;2:398-430.

45. Anderson MP, Ruthe R, Rodrigo LO. Evaluation of the effect of reprocessing on the structure and properties of low density polyethylene/thermoplastic starch blends. Carbohydr Polym. 2016;136:210-5.

46. Supaphol P, Harnsiri W, Junkasem J. Effects of calcium carbonate and its purity on crystallization and melting behavior, mechanical properties, and processability of syndiotactic polypropylene. J Appl Polym Sci. 2004;92:201-12.

47. Tavanai H, Morshed M, Zarebini M, Rezve AS. A study of the nucleation effect of pigment dyes on the microstructure of mass dyed bulked continuous filament polypropylene. Iran Polym J. 2005;14:267-76.

48. Raimo M, Martuscelli E. Influence of titanium dioxide on crystallization behavior of an ethylene-propylene copolymer. J Appl Polym Sci. 2003;90:3409-16.

49. Rimez B, Rahier H, Van Assche G, Artoos T, Biesemans M, Van Mele B. The thermal degradation of poly(vinyl acetate) and poly(ethylene-co-vinyl acetate), part I: experimental study of the degradation mechanism. Polym Degrad Stab. 2008;93:800-10. 